\title{
PRARANCANG UNIT PENGOLAHAN LIMBAH CAIR PABRIK JEANS DENGAN TEKNOLOGI IRADIASI GAMMA
}

\author{
Okto Nugroho', Sugili Putra², Noor Anis Kundari ${ }^{3}$
}

1) Sekolah Tinggi Teknologi Nuklir, Yogyakarta, Indonesia, oktonugroho100@gmail.com

2) Sekolah Tinggi Teknologi Nuklir, Yogyakarta, Indonesia, sugiliputra@gmail.com

3) Sekolah Tinggi Teknologi Nuklir, Yogyakarta, Indonesia, nooranis@batan.go.id

\begin{abstract}
ABSTRAK
PRARANCANG UNIT PENGOLAHAN LIMBAH CAIR PABRIK JEANS DENGAN TEKNOLOGI IRADIASI GAMMA. Prarancang Unit Pengolahan Limbah Cair Pabrik Jeans dengan Teknologi Iradiasi Gamma. Penggunaan zat warna untuk pewarna tekstil menimbulkan masalah pencemaran lingkungan khususnya air tanah. Masalah pencemaran ini muncul karena zat warna menghambat sinar matahari untuk menembus permukaan air sehingga menganggu proses fotosintesis. Teknologi radiasi gamma hadir sebagai solusi permasalahan tersebut. Radiasi gamma ketika bereaksi dengan air akan menghasilkan spesi-spesi radikal yang sangat reaktif seperti radikal hidroksil, elektron terhidratasi, dan radikal hidrogen. Spesi-spesi radikal ini akan menyerang senyawa zat warna sehingga akan terjadi degradasi senyawa zat warna. Degradasi senyawa zat warna ini ditandai dengan semakin beningnya air dan merupakan fokus dari penelitian ini. Tingkat absorbansi sampel untuk penelitian ini dikarakterisasi dengan UV-Vis. Nilai konstanta kecepatan reaksi didapatkan sebesar $0,8568 / j a m$ dan merupakan reaksi orde satu. Unit pengolahan beroperasi selama 330 hari dalam 1 tahun dengan jumlah tenaga kerja 97 orang. Unit pengolahan limbah cair zat warna ini beroperasi secara kontinu. Limbah cair zat warna akan didegradasi di reaktor iradiasi dengan aktivitas sumber radioaktif yang digunakan sebesar $38778,44 \mathrm{Ci}$ dengan massa 34,37 gram. Analisis ekonomi diperlukan untuk menentukan kelayakan proyek ini. Untuk memulai proyek ini dibutuhkan biaya investasi total sebesar Rp. 302.214.868.272 dan total biaya produksi sebesar Rp. 60.192.080.967 dengan harga pegolahan limbah cair zat warna Rp. 1000 per kg. Dari analisis ekonomi didapatkan nilai BEP 29,97\% atau Rp. 39.515.210.597, ROI 17,60 \%, Payback Time 5,68 tahun, dan DCFROR 17,79 \%. Proyek ini layak dan menarik untuk dibangun.
\end{abstract}

Kata kunci: analisis ekonomi, degradasi limbah zat warna, teknologi iradiasi gamma

\section{ABSTRACT}

PRE-DESIGN OF JEANS FACTORY LIQUID WASTE TREATMENT UNIT WITH GAMMA IRRADIATION TECHNOLOGY. The use of dyes for textile dyes raises environmental pollution problems, especially groundwater. This pollution problem arises because dyes inhibit sunlight to penetrate the surface of the water which disrupts photosynthesis. Gamma radiation technology is present as a solution to these problems. Gamma radiation when reacting with water will produce highly reactive radical species such as hydroxyl radicals, hydrated electrons, and hydrogen radicals. These radical species will attack the dyestuff compound so that the dye substance degradation will occur. The degradation of the dyestuff compound is characterized by increasingly clear water and is the focus of this research. The absorbance level of the sample for this study was characterized by UV-Vis. The reaction rate constant value is 0.8568 I hour and is a first-order reaction. The processing unit operates for 330 days in 1 year with a manpower of 97 people. This dye wastewater treatment unit operates continuously. The liquid waste of the dyestuff will be degraded in the irradiation reactor with the activity of the radioactive source used at $38778.44 \mathrm{Ci}$ with a mass of 34.37 grams. Economic analysis is needed to determine the feasibility of this project. To start this profect a total capital investment of Rp. 302,214,868,272 and total production costs of Rp. 60,19,080,967 with the price of processing of dyestuff wastewater Rp. 1000 per $\mathrm{kg}$. From the economic analysis, the BEP value is $29.97 \%$ or Rp. 39,515,210,597, ROI $17.60 \%$, Payback Time 5.68 years, and DCFROR 17.79\%. This prolect is feasible and interesting to build.

Key words: economic analysis, dyestuff waste degradation, gamma irradiation technology 


\section{PENDAHULUAN}

Pewarna adalah zat warna-warni yang dirancang untuk memberi bahan seperti kain, kertas, atau warna apa pun untuk warna. Ini dimungkinkan karena pewarna dapat menempel pada bahan yang bisa diterima. Pewarna telah digunakan oleh manusia selama lebih dari seribu tahun untuk berbagai aplikasi. Pewarna sintetis baru-baru ini ditemukan dan produksinya dalam skala besar dimulai karena kenaikan permintaan pewarna. Saat ini, pewarna sintetis telah menjadi bahan penting yang banyak digunakan untuk memberi warna pada tekstil, kosmetik, plastik dan pencetakan. Banyak limbah berwarna yang mengandung pewarna dilepaskan dari industri makanan, kulit, tekstil, dan pewarna. Industri tekstil sebagian besar memproduksi limbah yang terkontaminasi dengan pewarna. Industri tekstil (54\%) melepaskan jumlah limbah zat warna paling besar, industri pewarna $(21 \%)$, industri kertas dan pulp (10\%), industri cat dan penyamakan (8\%), dan industri manufaktur pewarna $(7 \%)[1]$.

Polutan organik yang berbeda dalam sumber air dan tanah ditemukan mengandung pewarna residu. Pewarna azo adalah pewarna yang paling disukai digunakan di sektor industri, mengandung satu atau lebih gugus azo yang dapat menahan pemecahan zat warna dan menumpuk di lingkungan pada konsentrasi tinggi. Ketika pewarna hadir dalam sistem air, penetrasi sinar matahari berkurang yang mengganggu aktivitas fotosintesis yang mengakibatkan penurunan kualitas air, kelarutan gas dan menyebabkan efek toksik akut pada flora dan fauna air. Sebagian besar pewarna dan produk penguraiannya yang dilepaskan dari air limbah beracun, karsinogenik, dan mutagenik bagi manusia dan bentuk kehidupan lainnya [2]. Dengan demikian, menghilangkan warna dari industri tekstil dan limbah industri manufaktur zat warna adalah masalah lingkungan yang tinggi. Banyak metode pengolahan air limbah seperti oksidasi kimia, koagulasi, filtrasi, adsorpsi, dan elektrolisis telah digunakan untuk menghilangkan pewarna dari limbah air limbah sebelum dibuang [2,3].

Industri pembuatan pewarna mewakili bagian yang relatif kecil dari keseluruhan industri kimia. Di seluruh dunia produksi pewarna hampir 800.000 ton per tahun. Sekitar
10-15\% pewarna sintetis hilang selama proses industri tekstil yang berbeda [4]. Jumlah produksi tekstil di Indonesia pada tahun 2011 sampai 2015 disajikan pada Tabel 1.

Tabel. 1. Jumlah Produksi Tekstil di Indonesia [5]

\begin{tabular}{cccc}
\hline Tahun & $\begin{array}{c}\text { Jumlah } \\
\text { Perusahaan }\end{array}$ & Kapasitas (ton) & $\begin{array}{c}\text { Jumlah Produksi } \\
\text { (ton) }\end{array}$ \\
\hline 2011 & 4811 & 8859165 & 6419196 \\
2012 & 4937 & 9148167 & 6893647 \\
2013 & 5178 & 10214396 & 7463198 \\
2014 & 5285 & 10252121 & 7021991 \\
2015 & 5273 & 10854594 & 6278203 \\
\hline
\end{tabular}

Teknologi iradiasi, sebagai proses oksidasi lanjut, telah menjadi sebuah proses yang menjanjikan untuk pengolahan limbah air buangan berbahaya. Warna pada umumnya akan berubah ketika terpapar radiasi ionisasi [3]. Metode iradiasi gamma menghasilkan ${ }^{*} \mathrm{OH}$ radikal, elektron terhidratasi, dan radikal hidrogen yang akan menyerang senyawa organik dengan cepat dan kuat [4].

Secara umum terdapat empat kategori berdasarkan desain fasilitas dan desain akses serta proteksi radiasi material radioaktif. Iradiator kategori IV merupakan iradiator dengan akses manusia yang terkendali. Sumber yang teah tersegel disimpan dalam kolam penyimpanan yang diisi dengan air. Sumber terlindungi saat tidak digunakan dan pada saat digunakan sumber terbuka dalam sebuah volume radiasi yang dijaga tidak dapat diakses oleh manusia melalui sistem kendali masuk [5]. Pada penelitian ini merancang pabrik pengolahan limbah zat warna dengan memodifikasi iradiator kategori IV.

\section{Iradiasi Gamma}

Radiolisis air oleh ionisasi radiasi (contoh : Sinar- $\gamma$ dari Co-60) menimbulkan pembentukan elektron terhidratasi $\left(\mathrm{e}_{\mathrm{aq}}{ }^{-}\right), \mathrm{H}^{+}$, $\mathrm{OH}^{-}, \mathrm{H}^{*},{ }^{*} \mathrm{OH}, \mathrm{H}_{2}, \mathrm{H}_{2} \mathrm{O}_{2}, \mathrm{O}_{2}{ }^{*-}$ [6] konsentrasi spesi-spesi tersebut tergantung pada energi iradiasi gamma, laju absorpsi, $\mathrm{pH}$ larutan, dan suhu [7]. Ketika air berinteraksi dengan radiasi gamma, maka terdekomposisi membentuk campuran radikal pereduksi primer dan radikal pengoksidasi primer $\left(\mathrm{OH}^{*}, \mathrm{e}_{\mathrm{aq}}^{-}, \mathrm{H}^{*}\right)$ serta produk molekuler $\left(\mathrm{H}_{2}\right.$ dan $\left.\mathrm{H}_{2} \mathrm{O}_{2}\right)$ [8].

Metode iradiasi gamma menghasilkan ${ }^{*} \mathrm{OH}$, elektron terhidratasi, dan radikal hidrogen yang akan menyerang senyawa organik dengan 
cepat dan kuat [4]. Tanpa adanya $\mathrm{O}_{2}$, umur radikal pereduksi $\left(\mathrm{H}^{*}\right.$ dan $\left.\mathrm{e}_{\mathrm{aq}}{ }^{-}\right)$meningkat. Radikal tersebut kemudian dapat [9]:

1. Bereaksi dengan diri sendiri dan berkontribusi dalam pembentukan $\mathrm{H}_{2}$ sekunder, reaksi terjadi pada $\mathrm{pH} 13$ mengikuti Pers. (1) dan (2).

$$
\begin{gathered}
\mathrm{e}_{\mathrm{aq}}^{-}+\mathrm{e}_{\mathrm{aq}}^{-} \rightarrow \mathrm{H}_{2}+2 \mathrm{OH}^{-} \\
\mathrm{e}_{\mathrm{aq}}^{-}+\mathrm{H}^{*} \rightarrow \mathrm{H}_{2}+\mathrm{OH}^{-}
\end{gathered}
$$

2. Terlibat dalam versi dasar reaksi berantai Allen, yang mengarah pada rekombinasi $\mathrm{H}_{2}$ dan membatasi konsentrasinya seperti pada Pers. (3) dan (4).

$$
\begin{gathered}
\mathrm{O}^{*-}+\mathrm{H}_{2} \rightarrow \mathrm{e}_{\mathrm{aq}}^{-} \\
\mathrm{e}_{\mathrm{aq}}{ }^{-}+\mathrm{HO}_{2}^{-} \rightarrow \mathrm{H}_{2} \mathrm{O}+\mathrm{O}^{*-}+\mathrm{HO}^{-}
\end{gathered}
$$

\section{Kinetika Degradasi Zat Warna}

Pada degradasi terinduksi oleh radiasi, spesi radiolisis pengoksidasi primer yang terbentuk selama proses radiolisis air menginisiasi degradasi polutan organik. Spesi pereduksi sekunder yang terbentuk selama proses radiolisis air dapat terkonversi menjadi spesi pengoksidasi dengan penambahan oksigen atau hidrogen peroksida. Degradasi senyawa organik dapat didekati dengan model kinetika orde 1 semu [10] seperti pada Pers. (5) dan (6).

$$
\begin{gathered}
C=C_{0} e^{-d D} \\
-\ln \left(\frac{C}{C_{0}}\right)=d D
\end{gathered}
$$

Dengan $\mathrm{C}_{0}$ adalah konsentrasi zat warna sebelum iradiasi; $\mathrm{C}$ adalah konsentrasi zat warna setelah iradiasi, d adalah konstanta dosis, dan $\mathrm{D}$ adalah dosis iradiasi yang diperlukan untuk mencapai konsentrasi yang diperlukan. Jika - $\ln \left(\mathrm{C} / \mathrm{C}_{0}\right)$ diplotkan versus $\mathrm{D}$, konstanta dosis merupakan slope [11].

Untuk membuat perancangan pabrik pengolahan limbah zat warna dengan iradiasi gamma, maka diperlukan nilai konstanta kecepatan reaksi degradasi zat warna yang dihitung menggunakan Pers. (12).

$$
\begin{aligned}
& \mathrm{H}_{2} \mathrm{O} \stackrel{\text { radiolisis }}{\longrightarrow}[0,28] \mathrm{OH}^{*}+[0,06] \mathrm{H}^{*}+ \\
& {[0,27] e_{e q}{ }^{-}+[0,05] \mathrm{H}_{2}+[0,07] \mathrm{H}_{2} \mathrm{O}_{2}+[0,27] H^{+}} \\
& \begin{array}{c}
(7) \\
A+\mathrm{OH}^{*}+H^{*}+e_{a q}^{*} \rightarrow \text { Produk degradasi (8) } \\
\mathrm{e} \\
-r_{A}=k C_{A}
\end{array}
\end{aligned}
$$

$$
\begin{gathered}
-\frac{d C_{A}}{d t}=k C_{A} \\
-\int_{C A 0}^{C A} \frac{d C_{A}}{d t}=\int_{0}^{t} k d t=k \int_{0}^{t} d t \\
\ln \frac{C_{A 0}}{C_{A}}=k t
\end{gathered}
$$

Dengan memplotkan $\ln \left[\mathrm{C}_{\mathrm{A} 0} / \mathrm{C}_{\mathrm{A}}\right]$ vs $\mathrm{t}$ memberikan garis lurus. Pers. (12) dapat dianalogikan dengan Pers. (6) sebagai kinetika reaksi orde 1 semu. Kinetika reaksi orde 1 semu merupakan model kinetika yang umumnya terjadi pada degradasi senyawa zat warna oleh radiasi gamma.

\section{METODE}

\section{Waktu dan Tempat}

Pertama pastikan bahwa Anda menggunakan template resmi yang diberikan oleh redaksi JFN baik melalui email atau download di website. Penelitian dilakukan mulai bulan April-Juli 2019. Penelitian dilakukan di Laboratorium Kimia Analisis, Laboratorium Instrumentasi Kimia, dan Laboratorium Kimia Radiasi STTN BATAN Yogyakarta.

\section{Bahan dan Alat}

Bahan yang digunakan dalam penelitian ini adalah limbah cair zat warna jeans naptol dari naptol jeans Jogja, larutan $\mathrm{HCl} \mathrm{0,01 \%} \mathrm{dan}$ larutan $\mathrm{H}_{2} \mathrm{O}_{2} 1 \%$. Alat yang digunakan pada penelitian ini adalah Iradiator gamma STTNBATAN Yogyakarta, neraca analitik (Mettler Toledo), alat-alat gelas laboratorium, serta karakterisasi dengan instrumen UV-Vis STTNBATAN

\section{Prosedur Penelitian}

\section{Penyiapan Bahan}

Limbah cairzat warna dikondisikan dengan menambahkan larutan $\mathrm{HCl} 0,01 \%$ dan larutan $\mathrm{H}_{2} \mathrm{O}_{2} 1 \%$ dengan perbandingan volume limbah: $\mathrm{HCl}: \mathrm{H}_{2} \mathrm{O}_{2}=1: 2: 1$.

\section{Proses Iradiasi}

Sampel dimasukkan ke dalam ruang iradiasi iradiator gamma sumber Co-60 dan 
diiradiasi dengan dosis 4 kGy, 8 kGy, 12 kGy, 16 kGy, 20 kGy, dan 24 kGy.

\section{Karakterisasi UV-Vis}

Limbah cair zat warna yang telah diiradiasi dikarakterisasi dengan UV-Vis STTN-BATAN, sebelumnya sudah dibuat kurva larutan standar sehingga konsentrasi limbah cair zat warna dapat teramati.

\section{HASIL DAN PEMBAHASAN}

\section{Konstanta Kecepatan Reaksi}

Konsentrasi limbah cair zat warna dikarakterisasi menggunakan spectrometer UV-Vis dengan metode kurva standar kalibrasi. Tabel 2. menunjukkan hasil penghitungan konsentrasi limbah cair zat warna.

Tabel. 2. Konsentrasi Limbah Cair Zat Warna setelah Iradiasi

\begin{tabular}{ccc}
\multicolumn{3}{c}{ Warna setelah Iradiasi } \\
\hline \multirow{2}{*}{ Waktu (Jam) } & ABS & Konsentrasi (mg/mL) \\
\hline 0 & 0,628 & 0,1171 \\
1 & 0,213 & 0,0397 \\
\hline
\end{tabular}

\begin{tabular}{ccc}
\hline Waktu (Jam) & ABS & Konsentrasi $(\mathrm{mg} / \mathbf{m L})$ \\
\hline 2 & 0,089 & 0,0166 \\
3 & 0,029 & 0,0054 \\
4 & 0,014 & 0,0026 \\
5 & 0,010 & 0,0019 \\
\hline
\end{tabular}

Dari hasil plot pada program microsoft excel didapatkan orde reaksi yang paling mendekati linear $\left(R^{2}=1\right)$ adalah orde reaksi 1 maka hubungannya adalah waktu iradiasi (jam) vs $\ln \left(\mathrm{C}_{\mathrm{A} 0} / \mathrm{C}_{\mathrm{A}}\right)$ yang ditunjukkan oleh Tabel 3 dan Gambar 1. Berdasarkan Gambar 1. Diperoleh persamaan $\mathrm{y}=0,8568 \mathrm{x}+0,2003$ dengan $R^{2}=0,9783$. Nilai konstanta kecepatan reaksi degradasi limbah cair zat warna adalah $0,8568 \mathrm{jam}^{-1}$.

Tabel. 3. Penentuan Orde Reaksi Degradasi Limbah Cair Zat Warna

\begin{tabular}{cc}
\hline Waktu (Jam) & $\ln \left(\mathrm{C}_{\mathrm{AO}} / \mathrm{C}_{\mathrm{A}}\right)$ \\
\hline 0 & 0,00000 \\
1 & 1,08125 \\
2 & 1,95390 \\
3 & 3,07524 \\
4 & 3,80348 \\
5 & 4,13996 \\
6 & 3,87759 \\
\hline
\end{tabular}

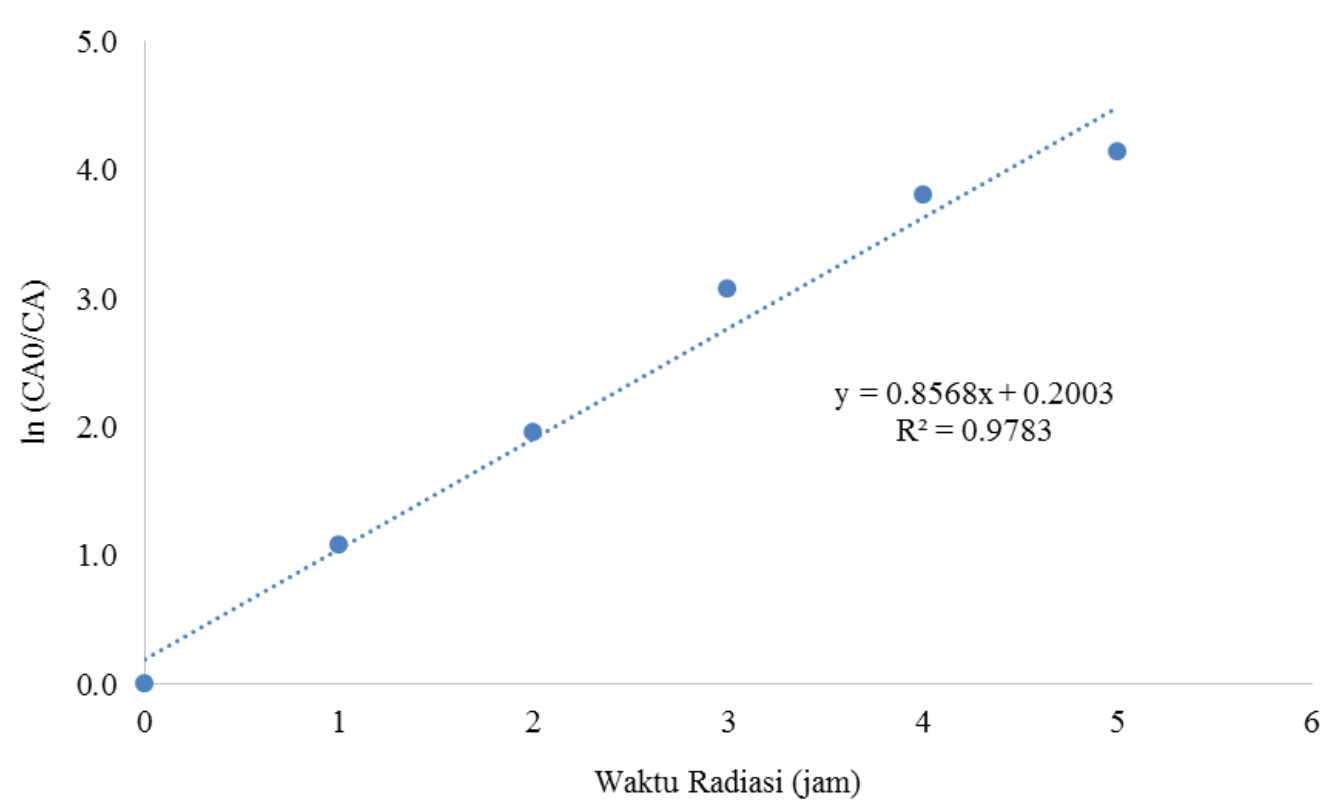

Gambar. 1. Diagram Blok Proses Unit Pengolahan Limbah Cair Zat Warna

\section{Neraca Massa}

Proses pengolahan limbah cair zat warna menggunakan teknoogi iradiasi gamma diawali oleh penggumpulan limbah cair zat warna. Tangki penampungan awal untuk menampung limbah cair zat warna memiliki ukuran 7 kali kapasitas maksimum unit. Dasar pertimbangan pemilihan ukuran ini adalah agar proses pengolahan bisa terus berjalan tanpa harus menunggu pelanggan datang, maka tangki disediakan ukuran 7 kali lebih besar dari kapasitas unit. 
Limbah cair zat warna di-treatment terlebih dahulu dengan menambahkan larutan $\mathrm{H}_{2} \mathrm{O}_{2} \quad 1 \%$ dan $\mathrm{HCl} 10,01 \%$. Dasar pertimbangan untuk penambahan kedua larutan tersebut adalah dari percobaan-percobaan yang telah dilakukan sebelumnya. Untuk menyiapkan larutan $\mathrm{H}_{2} \mathrm{O}_{2} 1 \%$ dan $\mathrm{HCl} 0,01 \%$ dari larutan pekatnya $\left(\mathrm{H}_{2} \mathrm{O}_{2} 35 \%\right.$ dan $\mathrm{HCl}$ $37 \%$ ) adalah dengan menambahkan tangki pelarutan. Proses pealrutan $\mathrm{H}_{2} \mathrm{O}_{2}$ dan $\mathrm{HCl}$ berlangsung secara batch selama 1 hari sekali pembuatan larutannya. Limbah cair zat warna setelah diolah kemudian diiradiasi pada reaktor iradiasi. Reaktor iradiasi merupakan reaktor jenis kontinu. Air limbah hasil iradiasi ditampung pada tangki penampungan akhir yang kemudian akan di buang ke sungai. Gambar 1. menunjukkan uraian proses pada unit ini dan Gambar 2. menunjukkan neraca massa pada unit ini.

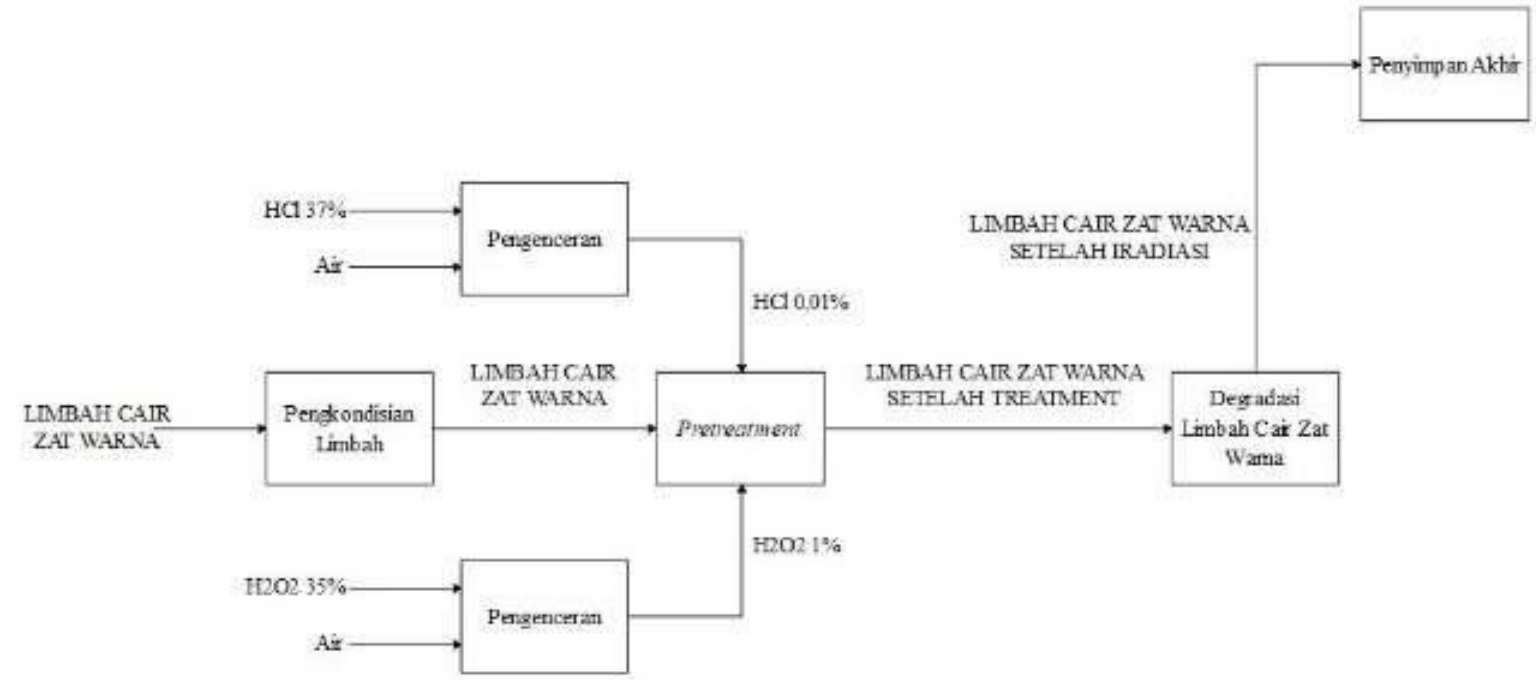

Gambar. 2. Diagram Blok Proses Unit Pengolahan Limbah Cair Zat Warna

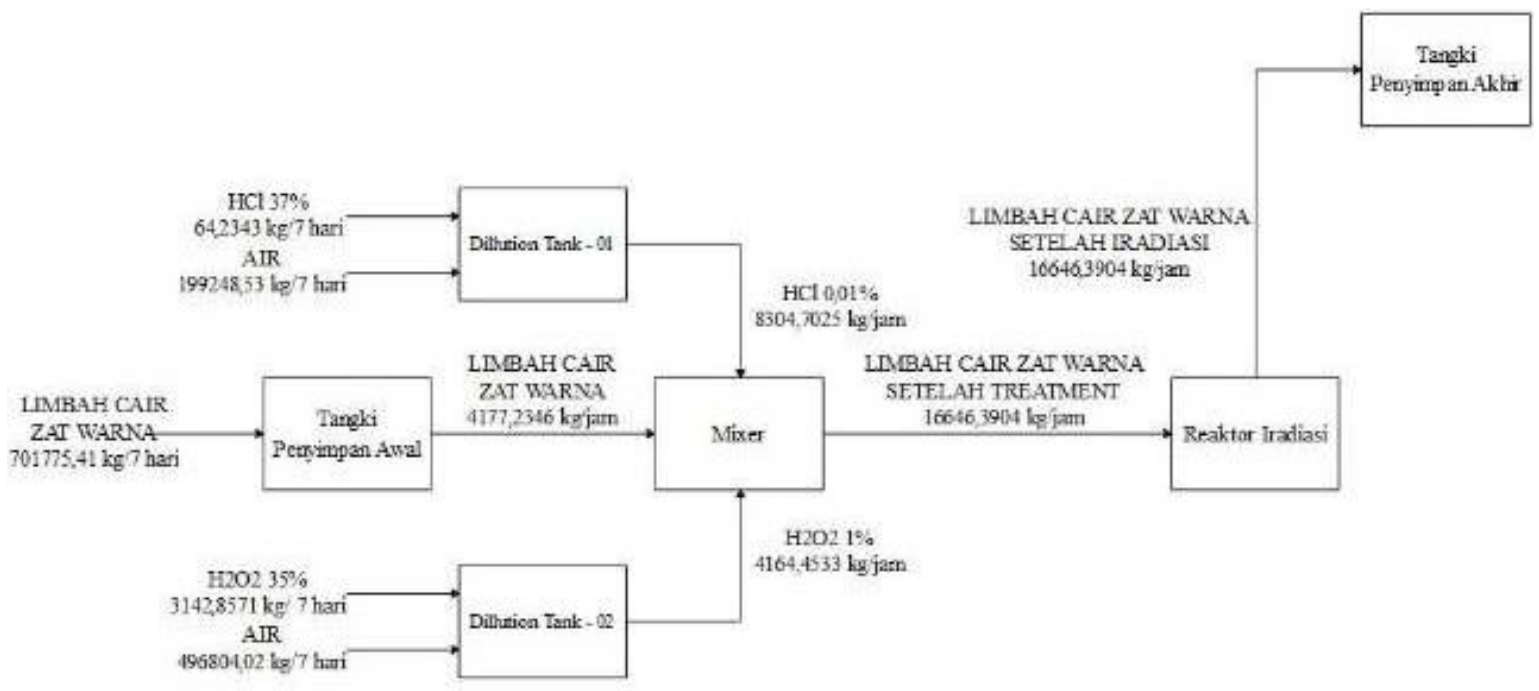

Gambar. 3. Neraca Massa Unit Pengolahan Limbah Cair Zat Warna

\section{Neraca Energi}

Proses pengolahan limbah cair zat warna dalam perancangan ini adalah menggunakan radiasi gamma yang berasal dari sumber radioaktif Co-60. Limbah cair zat warna setelah di treatment terlebih dahulu tidak mengalami perubahan suhu pada saat proses radiasi berlangsung. Limbah cair zat warna yang akan diolah dengan menggunakan radiasi gamma, sebelumnya di treatment terlebih dahulu menggunakan larutan $\mathrm{HCl} 0,01 \%$ dan larutan $\mathrm{H}_{2} \mathrm{O}_{2} 1 \%$. Larutan tersebut disiapkan terlebih dahulu dengan cara mengencerkan larutan $\mathrm{HCl} 37 \%$ dan larutan $\mathrm{H}_{2} \mathrm{O}_{2} 35 \%$ dengan air, pada proses pengeneran ini tidak terjadi perubahan suhu larutan. Proses treatment menggunakan kedua larutan tersebut tidak 
merubah suhu limbah ataupun suhu larutan $\mathrm{HCl}$ dan $\mathrm{H}_{2} \mathrm{O}_{2}$. Seluruh proses pengolahan limbah cair zat warna ini tidak menggunakan heat exchanger, boiler, pendingin, steam, dan sejenisnya. Oleh karena itu neraca energi tidak dihitung pada perancangan ini, karena tidak diperlukan.

\section{Spesifikasi Peralatan}

Reaktor Iradiasi (R - 01)

$\begin{array}{lll}\text { Fungsi } & : & \text { untuk mendegradasi } \\ & \text { limbah cair zat warna } \\ \text { Bahan konstruksi } & : & \text { beton } \\ \text { Bentuk tangki } & : & \text { bak berlapis-lapis } \\ & \text { dengan alas dan tutup } \\ & \text { datar }\end{array}$

Bahan konstruksi beton dipilih karena beton memiliki harga yang lebih murah dibandingkan dengan perisai lainnya (contoh $\mathrm{Pb}$ dan $\mathrm{Al}$ ), selain itu beton juga bisa berfungsi sekaligus sebagai dinding reaktor (dalam hal ini reaktor berbentuk seperti bak yang berlapis-lapis). Perancangan bak yang berlapis bertujuan untuk memperlama waktu iradiasi limbah selain itu juga berfungsi sebagai perisai agar perisai terluar tidak terlalu tebal. Ketika reaktor iradiasi tidak beroperasi maka sumber akan turun kebawah yang berisi air dan dilapisi dinding beton.

\begin{tabular}{lll} 
Kondisi operasi & $:$ & Suhu $27^{\circ} \mathrm{C}$, Tekanan \\
& & $1 \mathrm{~atm}$ \\
Jumlah & $:$ & 1 unit \\
Kapasitas & $:$ & $153,4456 \mathrm{~m}^{3}$ \\
Panjang & $:$ & $5,5398 \mathrm{~m}$ \\
Lebar & $:$ & $5,5398 \mathrm{~m}$ \\
Tinggi & $:$ & $5,0000 \mathrm{~m}$ \\
Jumlah dinding & $:$ & 3 lapis \\
Waktu iradiasi & $:$ & 0,9241 jam \\
Aktivitas sumber & $:$ & $38,7784 \mathrm{kCi}$ \\
& & \\
Pompa Reaktor Iradiasi $(\mathrm{P}-09)$ \\
Fungsi & $:$ & memompa larutan \\
& & limbah cair zat warna \\
& & setelah di radiasi ke \\
& & Tangki Penampungan - \\
& & 02 \\
\multicolumn{1}{l}{ Bahan konstruksi } & Cast iron \\
Jenis Pompa & $:$ & Pompa Sentrifugal \\
Kondisi operasi & $:$ & Suhu $27{ }^{\circ} \mathrm{C}$, Tekanan 1 \\
& & atm \\
Jumlah & $:$ & 1 unit \\
Kapasitas & $:$ & $1,4 \mathrm{~m}^{3} / \mathrm{s}$ \\
Daya motor & $:$ & $1389,0783 \mathrm{~W}$
\end{tabular}

\section{Utilitas}

Utilitas merupakan unit penunjang utama dalam memperlancar jalanny suatu proses produksi. Dalam suatu pabrik, utilitas memegang peranan yang penting. Karena suatu proses produksi dalam suatu pabrik tidak akan berjalan dengan baik jika utilitas tidak ada. Oleh sebab itu, segala sarana dan prasarananya harus dirancang sedemikian rupa sehingga dapat menjamin kelangsungan operasi suatu pabrik. Berdasarkan kebutuhannya, utilitas pada Unit Pengolahan Limbah Cair Zat Warna menggunakan Teknologi Iradiasi Gamma adalah sebagai berikut :

1. Kebutuhan air

2. Kebutuhan tenaga listrik

Dalam proses produksi, air memegang peranan penting, baik untuk kebutuhan proses maupun kebutuhan domestik. Adapun kebutuhan air pada Unit Pengolahan Limbah Cair Zat Warna adalah sebagai berikut :

1. Air Proses

2. Air Domestik

Tabel. 4. Kebutuhan Air Proses dan Air Domestik

\begin{tabular}{cc}
\hline Nama Alat & Jumlah Air (kg/jam) \\
\hline Dilution Tank - 01 & 8302,0223 \\
Dilution Tank - 02 & 4033,5010 \\
Air Domestik & 124,0000 \\
\hline Total & 12335,5232 \\
\hline
\end{tabular}

Tabel. 5. Kebutuhan Tenaga Listrik

\begin{tabular}{|c|c|c|}
\hline No. & Nama Alat & Daya (Watt) \\
\hline 1 & Pompa Tank 01 & 398,61 \\
\hline 2 & $\begin{array}{l}\text { Pompa Dillution Tank } 01 \\
\text { Input Air }\end{array}$ & 556,41 \\
\hline 3 & $\begin{array}{c}\text { Pompa Dillution Tank } 01 \\
\text { Input } \mathrm{HCl}\end{array}$ & 3,14 \\
\hline 4 & $\begin{array}{c}\text { Pompa Dillution Tank } 01 \\
\text { Output }\end{array}$ & 521,66 \\
\hline 5 & $\begin{array}{c}\text { Pompa Dillution Tank } 02 \\
\text { Input Air }\end{array}$ & 322,70 \\
\hline 6 & $\begin{array}{c}\text { Pompa Dillution Tank } 02 \\
\text { Input } \mathrm{H}_{2} \mathrm{O}_{2}\end{array}$ & 163,62 \\
\hline 7 & $\begin{array}{l}\text { Pompa Dillution } \\
\text { Tank } 02 \text { Output }\end{array}$ & 306,45 \\
\hline 8 & $\begin{array}{l}\text { Pompa Mixer } 01 \\
\text { Output }\end{array}$ & 817,48 \\
\hline 9 & $\begin{array}{l}\text { Pompa Tank } 02 \\
\text { Input }\end{array}$ & 1389,07 \\
\hline 10 & $\begin{array}{l}\text { Pompa Tank } 02 \\
\text { Output }\end{array}$ & 1172,42 \\
\hline 11 & Pengaduk Tank 01 & 790,60 \\
\hline 12 & $\begin{array}{l}\text { Pengaduk Dillution } \\
\text { Tank } 01\end{array}$ & 97,98 \\
\hline 13 & $\begin{array}{l}\text { Pengaduk Dillution } \\
\text { Tank } 02\end{array}$ & 38,58 \\
\hline
\end{tabular}




\begin{tabular}{ccc}
\hline No. & Nama Alat & Daya (Watt) \\
\hline 14 & Pengaduk Mixer & 309,15 \\
& 01 & \\
15 & Reaktor Iradiator & 800,00 \\
\hline & Total & 7687,94 \\
\hline
\end{tabular}

\section{Instrumentasi}

Instrumen digunakan dalam industri kimia untuk mengukur variabel proses, seperti suhu, tekanan, kepadatan, viskositas, panas spesifik, konduktivitas, $\mathrm{pH}$, kelembaban, titik embun, tingkat cairan, laju aliran, komposisi kimia, dan kadar air. Dengan menggunakan instrumen yang memiliki tingkat kompleksitas yang bervariasi, nilai-nilai variabel-variabel ini dapat direkam secara terus-menerus dan dikendalikan dalam batas yang sempit.

Kontrol otomatis adalah norma di seluruh industri kimia, dan penghematan tenaga kerja yang dihasilkan dikombinasikan dengan peningkatan kemudahan dan efisiensi operasi memiliki lebih dari mengimbangi biaya tambahan untuk instrumentasi. Dalam kebanyakan kasus, kontrol dicapai melalui penggunaan komputer berkecepatan tinggi. Dalam kapasitas ini, komputer berfungsi sebagai alat vital dalam pengoperasian pabrik. Pemanfaatan efektif dari banyak instrumen yang digunakan dalam proses kimia dapat dicapai melalui kontrol terpusat, di mana satu ruang kontrol yang terletak di pusat digunakan untuk indikasi, pencatatan, dan pengaturan variabel proses. Papan panel telah dikembangkan yang menghadirkan representasi grafis dari proses dan memiliki kontrol instrumen dan indikator yang dipasang di lokasi yang sesuai dalam keseluruhan proses. Ini membantu operator baru untuk dengan cepat mengenal pentingnya pembacaan instrumen, dan lokasi yang cepat dari setiap varian operasional dimungkinkan [15]. Tabel 6. menunjukkan berbagai jenis instrumentasi yang digunakan.

Tabel. 6. Daftar Instrumentasi

\begin{tabular}{ccl}
\hline No. & Nama Alat & Jenis Instrumentasi \\
\hline 1 & Reaktor Iradiasi & $\begin{array}{l}\text { Flow Controller }(F C) \\
\text { Level Controller }(L C) \\
\text { Earthquake Detector }\end{array}$ \\
& Mixer tank & $\begin{array}{l}\text { Flow Controller (FC) } \\
\text { Level Controller }(L C)\end{array}$ \\
3 & Pompa & Flow Controller (FC) \\
4 & Dillution tank & Flow Controller (FC) \\
& Level Controller $(L C)$ \\
5 & Tangki penyimpanan & Level Controller $(L C)$ \\
\hline
\end{tabular}

\begin{tabular}{ll}
\hline No. Nama Alat & Jenis Instrumentasi \\
\hline & Visible Indicator $(\mathrm{VI})$ \\
\hline
\end{tabular}

Jenis-jenis instrumentasi yang digunakan pada Prarancang Unit Pengolahan Limbah Cair Zat Warna menggunakan Teknologi Iradiasi Gamma :

1. Pompa

Variabel yang dikontrol pada pompa adalah laju aliran (flow rate). Untuk mengetahui laju aliran pada pompa dipasang flow control (FC). Jika laju aliran pompa lebih besar dari yang diinginkan maka secara otomatis katup pengendali (control valve) akan menutup atau memperkecil pembukaan katup.

2. Tangki Penyimpanan Limbah Awal

Pada tangki ini dilengkapi dengan flow control (FC) yang berfungsi untuk mengontrol aliran limbah cair zat warna ke dalam tangki pretreatment dengan menggunakan pompa yang dilengkapi dengan valve yang berfungsi sebagai flow control (FC).

3. Tangki Penampungan Akhir

Pada tangki penampungan dilengkapi dengan level indicator (LI) yang berfungsi untuk menunjukkan ketinggian cairan hasil iradiasi yang masuk ke dalam tangki penampungan akhir. Selain level indicator (LI), tangki penampungan akhir juga dilengkapi dengan visible indicator (VI) untuk mengetahui tingkat warna cairan dan kejernihan cairan, ketika warna cairan sudah relatif tidak berwarna maka cairan akan dilepas ke lingkungan dan sebagian ke kolam ikan.

4. Reaktor Iradiasi Gamma

Reaktor adalah alat tempat berlangsunnya proses degradasi limbah cair zat warna setelah pretreatment yang akan menghasilkan cairan yang relatif tidak berwarna. Pada reaktor dilengkapi sensing elemen yang berfungsi untuk mendeteksi gempa bumi dan bias dilihat pada earthquake detector. Untuk mengendalikan ketinggian cairan dalam reaktor digunakan level control (LC) dengan tujuan agar tidak terjadi kelebihan muatan yang mengakibatkan terjadinya ketidakmerataan dosis.

5. Mixer Tank (Tangki Pretreatment)

Tangki Pencampur ini dilengkapi dengan pengendali ketinggian atau Level Controller (LC) yang berfungsi untuk mengontrol ketinggian cairan di dalam Tangki. Prinsip kerja dari Level Controller (LC) ini 
adalah dengan menggunakan pelampung (floater) sehingga isi tangki dapat terlihat dari posisi jarum penunjuk di luar Tangki yang digerakkan oleh pelampung.

\section{Dilution Tank}

Pada tangki ini dilengkapi dengan level control (LC) yang berfungsi untuk mengontrol ketinggian cairan di dalam tangki. Prinsip kerja dari level control (LC) ini adalah dengan menggunakan pelampung (floater) sehingga isi tangki dapat terlihat dari posisi jarum penunjuk di luar tangki yang digerakkan oleh pelampung. Jika isi tangki tinggal sedikit, maka diisi dengan menggunakan pompa yang dilengkapi dengan valve yang berfungsi sebagai flow control (FC).

\section{Lokasi dan Tata Letak}

Penentuan lokasi unit sangat menentukan kemajuan dan kelangsungan dari industri, baik pada masa sekarang maupun pada masa yang akan datang. Pemilihan yang tepat mengenai lokasi unit harus memberikan suatu perhitungan biaya produksi dan distribusi yang minimal serta pertimbangan sosiologi, yaitu pertimbangan dalam mempelajari sikap dan sifat masyarakat di sekitar lokasi unit.

Berdasarkan faktor-faktor tersebut, maka Unit Pengolahan Limbah Cair Zat Warna menggunakan Teknologi Iradiasi Gamma ini direncanakan berlokasi di daerah Sungai Citarum. Dasar pertimbangan dalam pemilihan lokasi pabrik adalah:

1. Keadaan Lingkungan/Kestabilan kondisi alam

2. Letak dari pasar dan kondisi pemasaran

3. Fasilitas transportasi

4. Kebutuhan tenaga listrik dan bahan bakar

5. Kebutuhan air

6. Tenaga kerja

7. Harga tanah dan bangunan

8. Kemungkinan perluasan dan ekspansi

9. Kondisi Iklim dan Cuaca

10. Masyarakat di sekitar pabrik

11. Perumahan

Tabel. 7. Rincian Luas Tanah

\begin{tabular}{clc}
\hline No. & Nama Bangunan & Luas $\left(\mathbf{m}^{\mathbf{2}}\right)$ \\
\hline 1 & Pos Keamanan & 150 \\
2 & Tempat Parkir & 200 \\
3 & Unit Pembangkit & 150 \\
& Listrik & \\
4 & Perkantoran & 200 \\
\hline
\end{tabular}

\begin{tabular}{clc}
\hline No. & Nama Bangunan & Luas $\left(\mathbf{m}^{\mathbf{2}}\right)$ \\
\hline 5 & Laboratorium & 150 \\
6 & Ruang Kontrol & 288 \\
7 & Daerah Proses & 3750 \\
8 & Unit Pengolahan Air & 125 \\
9 & Area Perluasan & 375 \\
10 & Kolam Ikan & 17 \\
11 & Kantin & 125 \\
12 & Poliklinik & 125 \\
13 & Perpustakaan & 125 \\
14 & Tempat Ibadah & 300 \\
15 & Taman & 200 \\
16 & Jalan & 500 \\
17 & Aula & 500 \\
18 & Pemadam Kebakaran & 125 \\
\hline
\end{tabular}

Tabel. 8. Rincian Luas Tanah

\begin{tabular}{|c|c|c|}
\hline No. & Nama Bangunan & Luas $\left(\mathrm{m}^{2}\right)$ \\
\hline 1 & Dewan Komisaris & 2 \\
\hline 2 & Direktur & 1 \\
\hline 3 & Manajer Proses & 1 \\
\hline 4 & $\begin{array}{l}\text { Manajer } \\
\text { Pengembangan dan } \\
\text { Pengadaan }\end{array}$ & 1 \\
\hline 5 & Manajer Keuangan & 1 \\
\hline 6 & $\begin{array}{l}\text { Manajer HRD \& } \\
\text { Marketing }\end{array}$ & 1 \\
\hline 7 & $\begin{array}{l}\text { Kepala Bagian } \\
\text { Marketing }\end{array}$ & 1 \\
\hline 8 & Kepala Bagian HRD & 1 \\
\hline 9 & Kepala Bagian HSE & 1 \\
\hline 10 & $\begin{array}{l}\text { Kepala Bagian Mesin } \\
\text { dan Utilitas }\end{array}$ & 1 \\
\hline 11 & Kepala Bagian R\&D & 1 \\
\hline 12 & $\begin{array}{l}\text { Kepala Bagian } \\
\text { Maintenance }\end{array}$ & 1 \\
\hline 13 & $\begin{array}{l}\text { Kepala Bagian } \\
\text { Keamanan }\end{array}$ & 1 \\
\hline 14 & Karyawan Proses & 35 \\
\hline 15 & $\begin{array}{l}\text { Karyawan Keuangan } \\
\text { dan Personalia }\end{array}$ & 8 \\
\hline 16 & Karyawan Pemasaran & 3 \\
\hline 17 & Dokter & 3 \\
\hline 18 & PKSR & 3 \\
\hline 19 & PPR & 3 \\
\hline 20 & Operator Iradiator & 6 \\
\hline 21 & Satpam & 12 \\
\hline 22 & Perawat & 4 \\
\hline \multirow[t]{2}{*}{23} & Petugas Kebersihan & 6 \\
\hline & Total & 97 \\
\hline
\end{tabular}

\section{Analisis Ekonomi}

Untuk mengevaluasi kelayakan berdirinya suatu unit dan tingkat pendapatannya, maka dilakukan analisa perhitungan secara teknik. Selanjutnya perlu juga dilakukan analisa terhadap aspek ekonomi dan pembiayaannya. Dari hasil analisa tersebut diharapkan berbagai kebijaksanaan dapat diambil untuk pengarahan secara tepat. Suatu 
rancangan pabrik dianggap layak didirikan bila dapat beroperasi dalam kondisi yang memberikan keuntungan. Berbagai parameter ekonomi digunakan sebagai pedoman untuk menentukan layak tidaknya suatu pabrik didirikan dan besarnya tingkat pendapatan yang dapat diterima dari segi ekonomi.

Sebelum pabrik industri dapat dioperasikan, sejumlah besar uang harus tersedia untuk membeli dan memasang mesin dan peralatan yang diperlukan. Tanah harus diperoleh, fasilitas layanan harus tersedia, dan pabrik harus dibangun lengkap dengan semua perpipaan, kontrol, dan layanan. Selain itu, dana diperlukan untuk membayar biaya yang terlibat dalam operasi pabrik sebelum pendapatan penjualan tersedia.

Modal yang diperlukan untuk memasok pabrik yang diperlukan dan fasilitas pabrik disebut investasi modal tetap (FCI), sedangkan yang diperlukan untuk pengoperasian pabrik disebut modal kerja (WC). Jumlah dari investasi modal tetap dan modal kerja dikenal sebagai total investasi modal (TCI). Porsi modal tetap dapat dibagi lagi menjadi investasi modal tetap manufaktur, juga dikenal sebagai biaya langsung, dan investasi kapitalisasi-tetap non- manufaktur, juga dikenal sebagai biaya tidak langsung [12].

Hasil analisis ekonomi adalah sebagai berikut:

Total modal $\quad$ : Rp. 302.214.868.272 investasi

Total biaya produksi : Rp. 60.192.080.967

Total pemasukan : Rp. 131.839.411.708

Keuntungan bersih : Rp. 47.645.474.943

Profit Margin : $\quad 51,63 \%$

Break even point $\quad$ : Rp. 39.515.210.597

(BEP)

Return of Investment : $\quad 17,60 \%$

Pay Back Time : 5,68 tahun

DCFR0R : $17,7998 \%$

Analisa ini dilakukan untuk mengetahui laju pengembalian modal investasi total dalam pendirian pabrik. Kategori resiko pengembalian modal tersebut adalah :

$\mathrm{ROI} \leq 15 \%$ risiko pengembalian modal rendah $15 \leq \mathrm{ROI} \leq 45 \%$ risiko pengembalian modal rata-rata

$\mathrm{ROI} \geq 45 \%$ resiko pengembalian modal tinggi

Dari hasil perhitungan diperoleh ROI sebesar $17,60 \%$ sehingga unit pengolahan limbah cair zat warna yang akan didirikan ini termasuk risiko laju pengembalian modal ratarata. Nilai annual variable production (biaya produksi langsung) sebesar Rp. 28.015.364.385 dan total pemasukan Rp. 131.839.411.708, maka nilai biaya produksi langsung didapatkan Rp. 212 per kg. Nilai BEP didapatkan 39.515.211 kg/tahun atau Rp. 39.515.210.597. atau $\mathrm{BEP}=29,97 \%$.

Dari data feasibilities [15]

1. BEP $\leq 50 \%$, pabrik layak (feasible)

2. $\mathrm{BEP} \geq 70 \%$, pabrik kurang layak (infeasible)

Berdasarkan perhitungan diperoleh nilai BEP sebesar 29,97\%, maka prarancangan unit pengolahan limbah cair zat warna ini layak. Nilai Total Capital Investment sebesar Rp. 302.214.868.272 dan keuntungan kotor sebesar Rp. 68.064.964.204 maka didaptkan nilai PBT sederhana sebesar 4,44 tahun kemudian setelah pajak $30 \%$ didapatkan nilai PBT sebesar 5,68 tahun. Seluruh modal investasi akan kembali selama 5,68 tahun unit beroperasi dengan kapasitas penuh. Nilai NPV setiap tahunnya selama umur proyek (20 tahun), untuk menentukan nilai DCFROR maka menggunakan cara trial dan error sehingga nilai NPV pada tahun terakhir proyek bernilai Rp. 0. Dari perhitungan trial dan error didapatkan nilai DCFROR untuk proyek ini sebesar $17,7998 \%$.

\section{KESIMPULAN}

Dari hasil perhitungan pada Prarancang Unit Pengolahan Limbah Cair Zat Warna menggunakan Teknologi Iradiasi Gamma dengan kapasitas $100 \mathrm{~m}^{3}$ per hari ini, maka dapat diambil kesimpulan sebagai berikut:

1. Pabrik direncanakan beroperasi selama 330 hari dalam setahun.

2. Lokasi pabrik yang direncanakan adalah di daerah dekat Sungai Citarum, Kabupaten Bandung, Jawa Barat dengan luas tanah yang dibutuhkan sebesar $7405 \mathrm{~m}^{2}$.

3. Jumlah tenaga kerja yang dibutuhkan untuk mengoperasikan unit pengolahan limbah cair zat warna sebanyak 97 orang. Bentuk badan usaha yang direncanakan adalah Perseroan Terbatas (PT) dan bentuk organisasinya adalah organisasi garis. 


\section{SARAN}

Analisis tingkat toksisitas hasil pengolahan dengan radiasi gamm untuk penelitian lebih lanjut dan dapat ditambahkan reaktor mikroorganisme untuk proses degradasi lebi lanjut.

\section{DAFTAR PUSTAKA}

1. V. Katheresan, K. Jibrail, dan Y. L. Sie, "Efficiency of various recent wastewater dye removal methods: a review", Journal of Environmental Chmical Engineering, vol. 6, pp. 4676-4697, 2018

2. A. Joshi, dan S. Nidhi, "Bacterial decolorization of reactiv red: strategic bioremediation of textile dye", International Journal of Current Microbiology and Applied Scince, vol. 7, pp. 147-156, 2018

3. I. I. Fasfous dan A. F. Nedal, "Removal of cibacron brilliant yellow 3G-P dye from aqueous solutions using coffee husks as non-conventional low-cost sorbent", International Journal of Chemical and Molecular Engineering, vol. 6, pp. 908914, 2012

4. M. A. Hassan dan A.E. Nemr, "Health and environmental impacts of dyes: mini review", American Journal of Environmental Science and Engineering, vol. 1, pp. 64-67, 2017

5. Asosiasi Pertekstilan Indonesia, Highlight of Indonesia Textile Product Industry, API, 2018

6. L. A. W. Abdou, O. A. Hakeim, M.S. Mahmoud, dan A. M. El-Naggar, "Comparative study between the efficiency of electron beam and gamma irradiation for treatment of the dye solution", Chemical Engineering Journal, vol. 168, pp. 752-758, 2011

7. K. E. A, Ibrahim, A. E. Abdalla, M. O. A. Mustafa, dan D. Solpan, "Radiolytic degradation of carbofuran by using gamma and gamma/hydrogen peroxide process", Radiation Physics and Chemistry, vol. 153, pp. 251-257, 2018

8. A. Satmoko, S. Budihardjo, T. Harjanto, dan Sanda, "Perhitungan dan penentuan spesifikasi komponen-komponen utama sistem pengangkat sumber gamma pada iradiator gamma BATAN 2x250 kCi", Seminar Nasional SDM Teknologi Nuklir VII Sekolah Tinggi Teknologi Nuklir Yogyakarta, pp. 263-268, 2011

9. S. Sanguanmith, J. Meesungneon, dan J. P. Jay-Gerin, "Time-dependent yield of $* \mathrm{OH}$ radicals in the low linear energy transfer radiolysis of water between 25 and $350^{\circ} \mathrm{C} "$, Chemical Physics Letters, vol. 588, pp. 82-86, 2013

10. S. M. Ghoreishan, S. M. Kang, R. R. G. Seta, M. Norouzi, S. C. Jang, H. J. Yun, S. T. Lim, Y. K. Han, C. Rob, dan Y. S. Huh, "y-Radiolysis as a highly efficient green approach to the synthesis of metal nano clusters : A review of mechanism and applications", Chemical Engineering Jaournal, vol. 360, pp. 1390-1406, 2018

11. R. Puspalata, S. Sumathi, P. Chandramohan, S. Bera, S. Rangarajan, R. Sudha, S. V. Narasimhan, dan S. Velmurugan, "Gamma radiation induced formation and characterization of the nanooxides of manganese", Radiation Physics and Chemistry, vol. 85, pp. 153-160, 2013

12. P. Bouniol, W. Guillot, V. Dauvois, W. Dridi, dan S. Le Caer, "Original behavior of pore water radiolysis in cement-based materials containing sulfide : coupling between experiments and simulations", Radiation Physics and Chemistry, vol. 150, pp. 172-181, 2018

13. V. C. Padmanaban, N. Selvaruju, V. N. Vasudevan, dan A. Achary, "Augmented radiolytic (60Co y) degradation of direct red 80 (Polyazo dye): optimization, reaction kinetics \& G-value interpretation", Reaction Kinetics, Mechanisms and Catalysis, vol. 125, pp. 433-447, 2018

14. L. Ning, T. Wang, M. Zheng, J. Lei, L. Tang, G. Hu, G. Xu, dan M. Wu, "Radiation induced degradation of antiepileptic drug primidone in aqueous solution", Chemical Engineering Journal, vol. 270, pp. 66-72, 2015

15. M. S. Peters, D. T. Klaus, dan E. W. Ronald, Plant Design and Economics for Chemical Engineers 5th edition, New York: McGraw-Hill, 2002 